\title{
Demographic and Clinico-Pathological Characteristics of Egyptian Patients with Cholangiocarcinoma
}

\section{Elsayed Mohamed Abdelaal ${ }^{1 *}$, Essam Elshimi ${ }^{1}$, Taha Yassin ${ }^{2}$, Osama Hegazy², Mohamed Saad ${ }^{1}$ and Gamal A Badra1 $^{1}$}

${ }^{1}$ Department of Hepatology, National Liver Institute, Menoufiya University, Egypt

${ }^{2}$ Department of Hepatobiliary Surgery, National Liver Institute, Menoufiya University, Egypt

\begin{abstract}
A study was conducted to identify the characteristic demographic and clinico-pathological features of Egyptian patients with CCA, in order to improve both early diagnosis and ultimate prognosis. We collected and reviewed the demographic, clinical, laboratory data and cholangiographic studies and treatment modalities of patients admitted with CCA in the National Liver Institute (NLI), Menoufiya University, Egypt between April 2008 and March 2010. In order to evaluate the life expectancy of patients, follow up analysis was done from the time of diagnosis until the end of the study march 2012. Results of the study showed that Ninety-two patients were admitted with CCA in the above mentioned period. The median age was 52.2 years. The patients constituted $52.2 \%$ distal CCA, $37 \%$ hilar CCA and $10.8 \%$ intrahepatic CCA. The prevalence of HCV antibody was $31 \%$. ERCP and PTD were the main procedures for palliative drainage, Surgery was done for 14 cases: Whipple's operation was done for 8 cases of distal CCA, surgical by pass for two cases of distal CCA, Hepatic resection was done for 4 cases of hilar CCA The mean survival time was 298 days with no significant difference in mean survival time between patients with different types of CCA. Cox proportional hazard model showed that the presence of liver cirrhosis was independent risk factors for worse survival with hazard ratio of 6.8. Age, sex, initial bilirubin level and type of the tumor were not significant factors affecting survival. Therefore, Egyptian patients with CCA presented at a younger age and had higher bilirubin level than other patients. They presented late, so that curative surgical resection was rarely feasible.
\end{abstract}

Keywords: Cholangiocarcinoma; Egyptian patients; Epidemiology; Hepatitis C virus

Abbreviations: CCA: Cholangiocarcinoma; ERCP: Endoscopic Retrograde Cholangio Pacreatography; HCV: Hepatitis C Virus; PCBs: Polychlorinated Biphenyls; PSC: Primary Sclerosing Cholangitis

\section{Introduction}

Cholangiocarcinoma (CCA) is a usually fatal malignancy that presents late and has a poor prognosis [1]. It is the second most common primary hepatic tumour and it is increasing in incidence and carries a high mortality [2]. Mortality rates from CCA have risen steeply and steadily over the past 30 years. The cause of this rise is unknown and does not appear to be explained simply by improvements in diagnosis [3]. The incidence rates of CCA vary greatly among different areas of the world, and this variation is related to the distribution of risk factors and probably reflects interplay between genetic differences and geographical risk factors [4]. There does not appear to be any epidemiological information that would suggest which patients are at either high or low risk for the development of this malignancy [1]. It is known that conditions causing chronic inflammation of the biliary tree predispose to CCA [5]. Primary sclerosing cholangitis (PSC) is the commonest known predisposing condition for CCA in the West and is a definite risk factor [6]. Chemical carcinogens have been implicated in the aetiology of CCA [7]. Environmental toxins such as dioxins, vinyl chloride and polychlorinated biphenyls (PCBs) have been suggested to play a role in the pathogenesis of CCA and may explain the continuing rising incidence [8]. Hepatitis $C$ virus infection has been also implicated in the aetiology of intrahepatic-cholangiocarcinoma [9].

\section{Aim of the Work}

Unfortunately, there are no studies dealing with the risk and prognostic factors of CCA in Egyptian patients. Hence, the aim of this study was to identify the characteristic demographic and clinicopathological features of Egyptian patients with CCA, in order to improve both early diagnosis and ultimate prognosis.

\section{Patients and Methods}

Sampling was performed after informed consent was obtained from each patient included in the study to use the samples and clinical data for research purposes after being informed about the nature of the study.

The study protocol conformed to the ethical guidelines of the 1975 Declaration of Helsinki as reflected in a priori approval by the National Liver Institute (NLI) human research committee.

We collected and reviewed the demographic and clinical data of patients admitted with CCA in the National Liver Institute (NLI), Menoufiya University, Egypt between Jan 2008 and March 2010. The reviewed parameters included: age, sex, clinical presentation, viral hepatitis B and C status, biochemical liver tests (bilirubin, serum aspartate aminotransferase [AST], serum alanine aminotransferase [ALT], alkaline phosphatase [ALP], gamma-glutamyl transpeptidase [GGT], Prothrombin Time [PT]), serum alpha-fetoprotein [AFP], carbohydrate antigen [CA] 19-9, and carcinoembryogenic antigen [CEA]), imaging and cholangiographic studies and treatment modalities.

In order to evaluate the life expectancy of patients, follow up analysis was done from the time of diagnosis until the end of the study March 2012.

*Corresponding author: Elsayed Mohamed Abdelaal, M.D Hepatology, Department of Hepatology, National Liver Institute, Menoufiya University, Egypt, E-mail: eabdelaal@yahoo.com

Received April 15, 2013; Accepted June 13, 2013; Published June 15, 2013

Citation: Abdelaal EM,Elshimi E, Yassin T, Hegazy O, Saad M, et al. (2013) Demographic and Clinico-Pathological Characteristics of Egyptian Patients with Cholangiocarcinoma. J Liver 2: 120. doi:10.4172/2167-0889.1000120

Copyright: (c) 2013 Abdelaal EM, et al. This is an open-access article distributed under the terms of the Creative Commons Attribution License, which permits unrestricted use, distribution, and reproduction in any medium, provided the original author and source are credited. 
Citation: Abdelaal EM,Elshimi E, Yassin T, Hegazy O, Saad M, et al. (2013) Demographic and Clinico-Pathological Characteristics of Egyptian Patients with Cholangiocarcinoma. J Liver 2: 120. doi:10.4172/2167-0889.1000120

Page 2 of 5

Statistical Analysis was performed using SPSS software, version 16 (SPSS, Inc., Chicago, IL). Comparison between groups was performed using non-parametric tests (Kruskal-Wallis and Mann Whitney tests) due to small sample size and lack of normal distribution. Differences in proportions of categorical data were tested by Chi-square test. Survival was assessed using the Kaplan-Meier method. Multivariate analysis was done using Cox proportional hazard method. A p value of less than 0.05 was considered significant.

\section{Results}

\section{Demographic and clinico-pathological characteristics}

Ninety-two patients were admitted to NLI diagnosed with CCA during the period between Jan 2008 and March 2010. The median age of the patients was 52.5 years with an age range of $32-80$ years. They consisted of $52(56.53 \%)$ males and $40(43.47 \%)$ females (Table 1).

The cases constituted 46 (50\%) cases of distal CCA, 36 (39.13\%) cases of hilar CCA, and 10 (10.8\%) cases of intra-hepatic (ICC) (Table 1). Four patients had PSC as demonstrated by ERCP. 22 (24\%) patients had liver cirrhosis. Hepatitis B surface antigen (HBsAg) was negative in all patients. Hepatitis C virus (HCV) antibody was positive in (27) $29.34 \%$ of patients (Table 2).

The mean value of CA $19-9$ was $1665.5 \pm 2390.5 \mathrm{U} / \mathrm{mL}$. The mean value of CEA was $5.0 \pm 3.1 \mu \mathrm{g} / \mathrm{L}$. AFP was elevated in 4 patients. There was no significant difference in the HCV status, biochemical or tumour markers between patients with different types of CCA. The biochemical and tumour markers results are shown in (Table 2).

Reviewing pathological data with surgery department revealed that
R0 resection was fulfilled in 3 cases of liver resection and 6 cases of Whipple.

In most cases the exposure to pollutants was not direct and clear as these toxins are present in the food and atmosphere in non-sensible matter.

The data of the staging along the TNM: Most cases underwent palliative treatment and extensive investigations were not done.

\section{Treatment modalities}

The type of therapeutic procedure depended on tumor expansion and clinical condition of the patients. If the tumor was respectable, surgery was the first choice of treatment for patients in good clinical condition. ERCP and PTD were the main procedures for palliative drainage. Surgery was done for 14 cases: Whipple's operation was done for 8 cases of distal CCA, surgical by pass for two cases of distal CCA. Hepatic resection was done for 4 cases of hilar CCA (Table 3).

Indeed, surgery was done in only 14 cases and R0 was fulfilled in only 9 cases which was a small no and was not statistically significant.

\section{Analysis of patients' survival and prognostic factors}

Patients' survival was estimated using Kaplan-Meier method. Kaplan-Meier curve is shown in Figure 1. The overall mean survival of the patients was 298 days. There was no significant difference in mean survival time between patients with different types of CCA. Causes of death were liver cell failure in 8 patients, septicemia in 12 patients and post-operative complications in one patient.

Multivariate analysis using Cox' proportional hazard model showed that the presence of liver cirrhosis was independent risk factors for

\begin{tabular}{|c|c|c|c|c|c|}
\hline & ICC & Hilar CCA & Distal CCA & All cases & $p$ value \\
\hline No of patients $(\%)$ & $10(10.8 \%)$ & $36(39.13 \%)$ & $46(50 \%)$ & 92 & \\
\hline $\begin{array}{l}\text { Age (years) } \\
\text { Median } \\
\text { (range) }\end{array}$ & $\begin{array}{c}42 \\
(37-47)\end{array}$ & $\begin{array}{c}56.5 \\
(36-67)\end{array}$ & $\begin{array}{c}52.5 \\
(29-80)\end{array}$ & $\begin{array}{c}52.5 \\
(29-80)\end{array}$ & $0.63^{*}$ \\
\hline $\begin{array}{l}\text { Sex: No (\%) } \\
\text { Male } \\
\text { Female }\end{array}$ & $\begin{array}{l}6(60 \%) \\
4(40 \%)\end{array}$ & $\begin{array}{c}20(55.5 \%) \\
16(44.44 \%)\end{array}$ & $\begin{array}{c}26(56.5 \%) \\
20(43.47 \%)\end{array}$ & $\begin{array}{l}52(56.53 \%) \\
40(43.47 \%)\end{array}$ & $0.93 *$ \\
\hline
\end{tabular}

Table 1: Demographic characteristics of patients with different types of cholangiocarcinoma. ${ }^{*} p$ value is non-significant.

\begin{tabular}{|c|c|c|c|c|c|}
\hline & ICC & Hilar CCA & Distal CCA & All cases & $p$ value \\
\hline No of patients (\%) & $10(10.8 \%)$ & $36(39.13 \%)$ & $46(50 \%)$ & 92 & \\
\hline $\begin{array}{l}\text { Bilirubin } \\
\text { No of patients with elevated bilirubin } \\
(\%)\end{array}$ & $\begin{array}{l}304.3 \pm 159.8 \mu \mathrm{mol} / \mathrm{L}(17.9 \\
\pm 9.4 \mathrm{mg} / \mathrm{dL}) 8(80 \%)\end{array}$ & $\begin{array}{l}370.6 \pm 156.4 \mu \mathrm{mol} / \mathrm{L}(21.8 \pm \\
9.2 \mathrm{mg} / \mathrm{dL}) 34(100 \%)\end{array}$ & $\begin{array}{l}314.5 \pm 132.6 \mu \mathrm{mol} / \mathrm{L}(18.5 \pm \\
7.8 \mathrm{mg} / \mathrm{dL}) 44(91 \%)\end{array}$ & $\begin{array}{l}334.7 \pm 144.5 \mu \mathrm{mol} / \mathrm{L}(19.6 \pm \\
8.5 \mathrm{mg} / \mathrm{dL}) 86(93.4 \%)\end{array}$ & $0.67^{*}$ \\
\hline ALP (IU/L) & $390.8 \pm 271.7$ & $331.7 \pm 190.3$ & $641.6 \pm 412.3$ & $489.9 \pm 352.9$ & $0.01^{* *}$ \\
\hline $\begin{array}{l}\text { CA19-9 }(\mathrm{U} / \mathrm{mL}) \\
\text { No of patients with CA19-9 >100 (\%) }\end{array}$ & $1665.5 \pm 2390.54(40 \%)$ & $2754.2 \pm 4827.820(58.8 \%)$ & $449.3 \pm 661.516(33 \%)$ & $1499.6 \pm 3291.640(43.5 \%)$ & $0.34^{*}$ \\
\hline CEA $(\mu \mathrm{g} / \mathrm{L})$ & $5.0 \pm 3.1$ & $54.8 \pm 178.2$ & $54 \pm 5.7$ & $26.8 \pm 117.4$ & $0.93^{*}$ \\
\hline AFP (ng/L) & $6.0 \pm 2.15$ & $47.5 \pm 165.6$ & $26.2 \pm 90.2$ & $32.7 \pm 122.1$ & $0.09^{*}$ \\
\hline HCV antibody & (6) $60 \%$ & $(13) 36.11 \%$ & (8) $17.39 \%$ & $27(29.34 \%)$ & $0.18^{*}$ \\
\hline
\end{tabular}

Table 2: Biochemical and tumour markers results in patients with different types of cholangiocarcinoma. All values are presented as mean \pm SD. ${ }^{*} p$ value is non-significant. ${ }^{* *} p$ value is significant.

\begin{tabular}{|l|c|c|c|}
\hline & ICC & Hilar CCA & Distal CCA \\
\hline Surgery & 0 & 4 & 10 \\
\hline Palliative treatment & 0 & 20 & 14 \\
$\quad$ ERCP & 4 & 12 & 26 \\
PTD & 6 & 0 & 10 \\
\hline No definitive treatment & 26 & 0 \\
\hline
\end{tabular}

Table 3: Treatment modalities in patients with different types of CCA. N.B. Many treatment modalities can be performed in the same patient. 


\section{Survival Function}

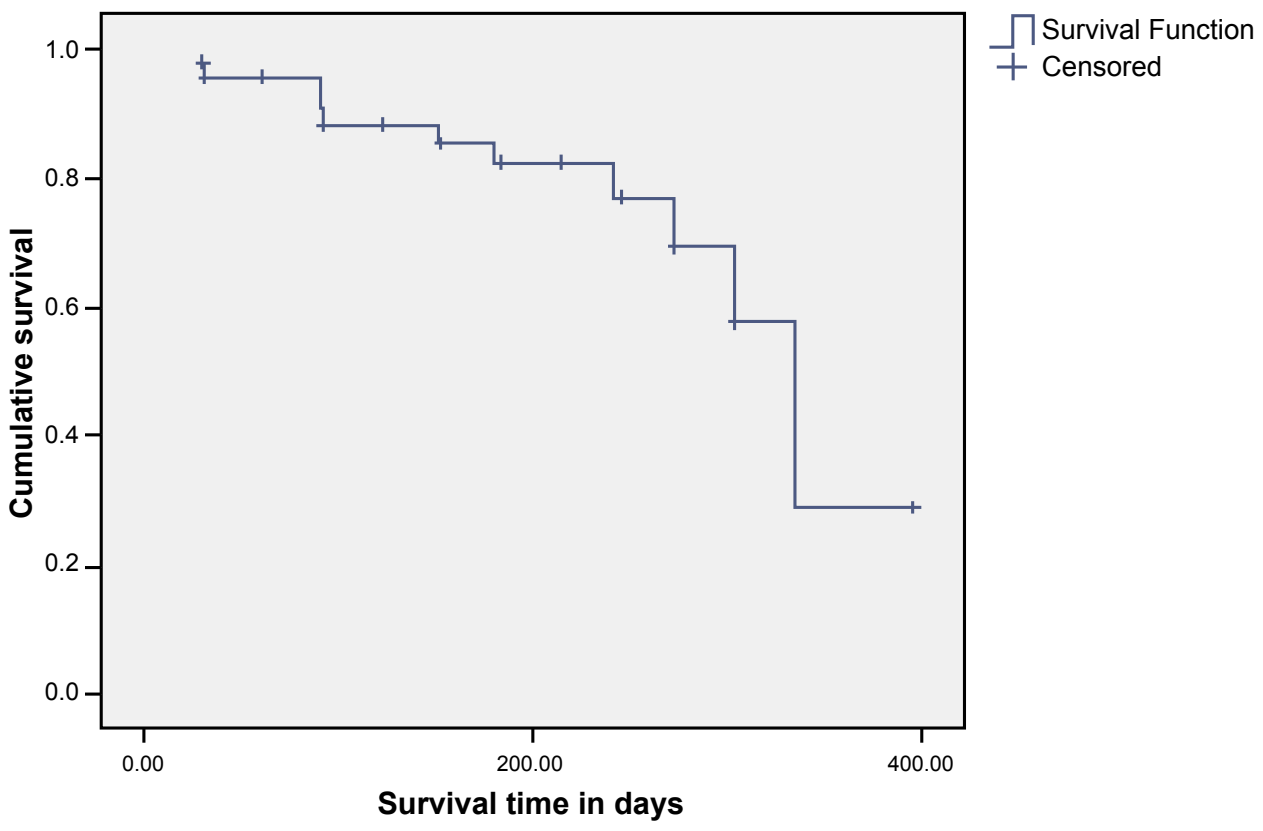

Survival Functions

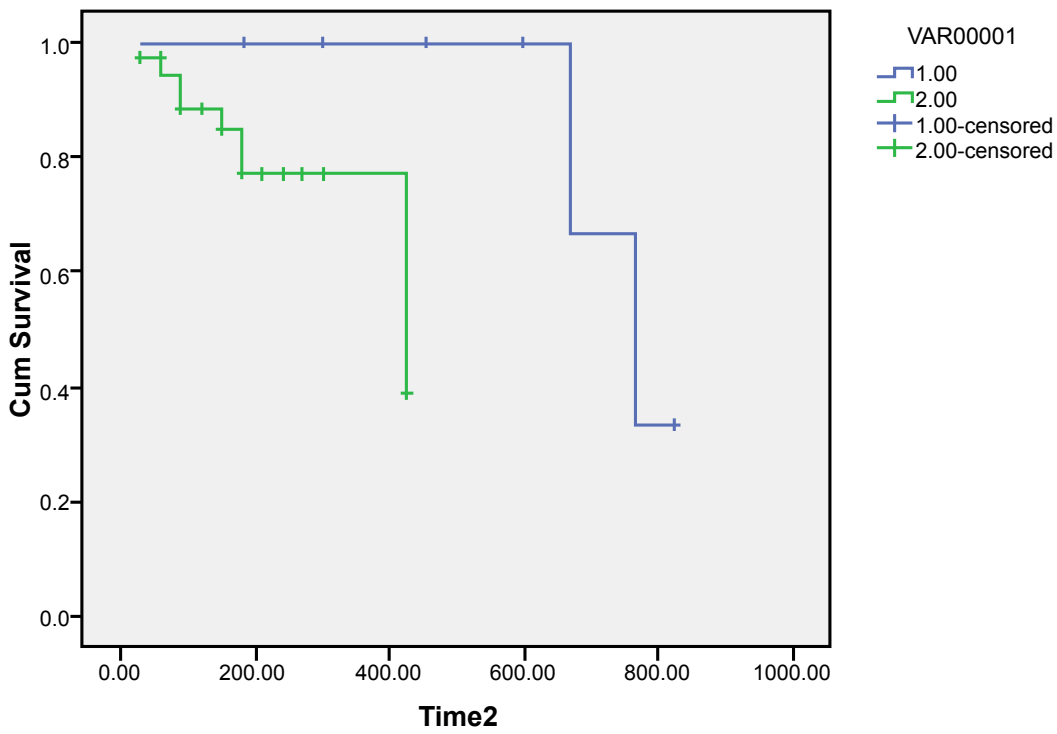

$P$ value $0.07 \mathrm{NS}$

1 = surgery

2 = palliative

Figure 1: Patients' Survival was Estimated using Kaplan-Meier Curve. The overall mean survival of the patients was 298 days. There was no significant difference in mean survival time between patients with different types of CCA.

worse survival with hazard ratio of 6.8. Age, sex, initial bilirubin level and type of the tumor were not significant factors affecting survival.

\section{Discussion}

CCA is the second most common primary hepatic cancer. Although its overall incidence is low, it is on the rise globally [10]. Known risk factors account for only a few cases. The most common risk factors for development of CCA are liver cirrhosis, viral hepatitis, PSC, choledocholithiasis, bile duct adenoma, parasitic biliary infestation and fibropolycystic liver disease [11].

In our cohort the most common risk factors were liver cirrhosis (23\%) and chronic HCV infection (29.34\%). PSC was present in only 
4 cases. The high prevalence of HCV infection in our cases may be expected owing to the high prevalence of chronic HCV infection in Egypt, but it is generally higher than in the general population which is estimated to be around $24 \%$ [12].

Infection with $\mathrm{HCV}$ or HBV has been suggested to be involved in the pathogenesis of CCA [13-15]. The prevalence of anti-HCV antibodies in patients with CCA was found to be $12.5 \%$ - $36 \%$ in these studies. Kobayashi et al. [13] reported that HCV related cirrhosis is a major risk factor for the development of CCA. HCV infection is a strong risk factor for Hepatocellular carcinoma (HCC). Given that hepatocytes and cholangiocytes have the same progenitor cell, it can be postulated that HCV can induce carcinogenesis in both cell types with same mechanism [16].

Pollutants and toxins may be implicated also in the pathogenesis of CCA. Most of the patients were residents of the Delta region which is reported to be seriously contaminated with heavy metals, pesticides, and polychlorinated biphenyls (PCBs) as a result of increasing discharge of untreated industrial wastes and agricultural irrigation wastewater [17-20]. Fishermen inhabiting this region suffer from high serum levels of the toxic substances lead, cadmium and mercury [21]. Exposure to pesticides is considered a risk factor for the development of many malignancies such as HCC, pancreatic cancer and colorectal cancer in Egyptian patients [22-24]. A similar role may be suspected also in the development of CCA $[8,25]$, which needs to be studied by examining more closely the environmental and occupational exposures, dietary intake, and family history of cancer in these patients. These data will be of particular importance in order to identify, prevent, and control potential environmental hazards.

The mean age of the patients with CCA was 53.17 years which is a younger age of presentation than in other series. CCA usually affects individuals in their $6^{\text {th }}$ or $7^{\text {th }}$ decades of life [26]. These data coincide with other studies which reported a younger age of cancer presentation in Egypt, such as pancreatic cancer [27], colorectal cancer and premenopausal breast cancer [28].

The estimated mean survival time in our cohort was 303 days which coincides with the reported studies. The reported mean survival time for patients with inoperable CCA is 145 - 360 days. Most patients die within 6-12 months of diagnosis [29,30]. Causes of death were mainly related to liver cell failure and septic complications.

Many factors influence patients' survival including: age, anatomic site, morphologic type and treatment modality [31].

Previous reports supported the importance of a curative surgical resection for long term survival. The achievement of $\mathrm{R} 0$ resection margin and the absence of lymph node involvement are significant prognostic factors affecting survival [32-34]. Because most of our patients were in advanced stage at the time of diagnosis, a curative resection was achieved in only a small number of patients.

This study has some potential limitations. Our data were dependent on hospital records which may limit the extrapolation of the statistics to other populations both within Egypt and outside. However, these methodologies are unavoidable at present, since the lack of populationbased cancer registration systems in developing countries, such as Egypt, makes cancer hospital records the main source of cancer statistics [28].

Information on environmental exposures was lacking. Had such information been available, it would have added a critical dimension to our study as regards to the exposure of pesticides and pollutants. This study may serve as a point of departure for future studies to identify the epidemiological characteristics and risk factors of CCA in Egyptian patients by examining more closely the environmental and occupational exposures, dietary intake, and family history of cancer in these patients.

\section{Conclusion}

Egyptian patients with cholangiocarcinoma presented at a younger age and had higher bilirubin level than other patients. They presented late, so that curative surgical resection was rarely feasible.

\section{References}

1. Khan SA, Davidson BR, Goldin RD, Heaton N, Karani J, et al. (2012) Guidelines for the diagnosis and treatment ofcholangiocarcinoma: an update. Gut 61: 1657-1669.

2. European HPB Association Consensus Conference on Cholangiocarcinoma HPB 2008; 2: 71-147.

3. Taylor-Robinson SD, Toledano MB, Arora S, Keegan TJ, Hargreaves S, et al. (2001) Increase in mortality rates from intra-hepatic cholangiocarcinoma in England and Wales1968-1998. Gut 48: 816-820.

4. Shaib $Y$ and El-Serag $H$ (2004) The epidemiology of cholangiocarcinoma Semin Liver Dis 24: 115-125.

5. Berthiaume E, Wands J (2004) The molecular pathogenesis of cholangiocarcinoma. Semin Liver Dis 24: 127-137.

6. Tyson G El-Serag H (2011) Risk Factors for Cholangiocarcinoma. Hepatology 54: 173-184

7. Sahani D, Prasad SR, Tannabe KK, Hahn PF, Mueller PR, et al. (2003) Thorotrast-induced cholangiocarcinoma: case report. Abdom Imaging 28: 7274.

8. Walker NJ, Crockett PW, Nyska A, Brix AE, Jokinen MP, et al. (2005) Doseadditive carcinogenicity of a defined mixture of "dioxin-like compounds". Environ Health Perspect 113: 43-48.

9. Yamamoto S, Kubo S, Hai S, Uenishi T, Yamamoto T, et al. (2004) Hepatitis C virus infection as a likely aetiology of intrahepatic cholangiocarcinoma. Cancer Sci 95: 5920-595.

10. Patel T (2001) Increasing incidence and mortality of primary intra-hepatic cholangiocarcinoma in the United States Hepatology 33: 1353-1357.

11. Khan S, Thomas H, Davidson B, Taylor-Robinson S (2005) Cholangiocarcinoma The Lancet 366 : 1303-1314.

12. Habib M, Mohamed MK, Abdel-Aziz F, Magder LS, Abdel-Hamid M, et al. (2001) Hepatitis C Virus Infection in a Community in the Nile Delta: Risk Factors for Seropositivity. Hepatology 33: 248-253.

13. Kobayashi M, Ikeda K, Saitoh S, Suzuki F, Tsubota A, et al. (2000) Incidence of primary cholangiocelluar carcinoma of the liver in Japanese patients with hepatitis C virus-related cirrhosis. Cancer 88: 2471-2477.

14. Donato F, Gelatti U, Tagger A, Favret M, Ribero ML, et al. (2001) Intra-hepatic cholangiocarcinoma and hepatitis $\mathrm{C}$ and $\mathrm{B}$ virus infection, alcohol intake, and hepatolithiasis: a case-control study in Italy. Cancer Causes Control 12: 959 964.

15. Yamamoto S, Kubo S, Hai S, Uenishi T, Yamamoto T, et al. (2004) Hepatitis C virus infection as a likely etiology of intrahepatic cholangiocarcinoma. Cancer Sci 95: 592- 595

16. Yin F, Chen B (1998) Detection of hepatitis $C$ virus RNA sequences in hepatic portal cholangiocarcinoma tissue by reverse transcription polymerase chain reaction. Chin Med J (Engl) 111: 1068- 1070.

17. Dekov V, Komy Z, Araujo F, Van Put A, Van Grieken R (1997) Chemical composition of sediments, suspended matter, river water and ground water of the Nile (Aswan-Sohag traverse). Sci Total Environ 201: 195-210

18. Abdel-Haleem A, Sroor A, El-Bahi S, Zohny E (2001) Heavy metals and rare earth elements in phosphate fertilizer components using instrumental neutron activation analysis. Appl Radiat Isot 55: 569- 573.

19. Reinhardt E, Stanley D, Schwarcz H (2001) Human-induced desalinization of 
Citation: Abdelaal EM,Elshimi E, Yassin T, Hegazy O, Saad M, et al. (2013) Demographic and Clinico-Pathological Characteristics of Egyptian Patients with Cholangiocarcinoma. J Liver 2: 120. doi:10.4172/2167-0889.1000120

Page 5 of 5

Manzala Lagoon, Nile Delta, Egypt: evidence from isotopic analysis of benthic invertebrates. J Coastal Res 17: 431- 442

20. Abdel-Sabour M (2001) Cadmium status in Egypt. J Environ Sci (China) 13: 351-360.

21. Osfor M, El-Dessouky S, El-Sayed A, Higazy R (1998) Relationship between environmental pollution in Manzala Lake and health profile of fishermen. Nahrung 42: 42- 45.

22. Ezzat S, Abdel-Hamid M, Eissa SA, Mokhtar N, Labib NA, et al. (2005) Associations of pesticides, $\mathrm{HCV}, \mathrm{HBV}$, and hepatocellular carcinoma in Egypt. Int J Hyg Environ Health; 208: 329-39.

23. Kriegel AM, Soliman AS, Zhang Q, El-Ghawalby N, Ezzat F, et al. (2005) Serum cadmium levels in pancreatic cancer patients from the East Nile Delta region of Egypt. Environ Health Perspect 113: 113- 119.

24. Soliman AS, Smith MA, Cooper SP, Ismail K, Khaled H, et al. (1997) Serum organo-chlorine pesticide levels in patients with colorectal cancer in Egypt. Arch Environ Health 52: 409- 415.

25. Shaib Y, El-Serag $H$ (2004) The epidemiology of cholangiocarcinoma. Semin Liver Dis; 24: 115-125.

26. Liu X, Zhou X, Zou S (2005) An analysis of 680 cases of cholangiocarcinoma from 8 hospitals. Hepatobiliary Pancreat Dis Int 4: 585- 588

27. Soliman AS, El-Ghawalby N, Ezzat F, Bondy ML, Soultan A, et al. (2002)
Unusually high rate of young-onset pancreatic cancer in the East Nile Delta region of Egypt. Int J Gastrointes Can 32: 143-151.

28. Soliman AS, Bondy ML, Raouf AA, Makram MA, Johnston DA, et al. (1999) Cancer mortality in Menofeia, Egypt: comparison with US mortality rates. Cancer Causes and Control 10: 349-354.

29. Zoepf T, Jakobs T, Arnold J, Apel D, Riemann J (2005) Palliation of nonresectable bile duct cancer: improved survival after photodynamic therapy. Am J Gastroenterol 100: 2426-2430.

30. Weber A, Landrock S, Schneider J, et al.( 2007) Long-term outcome and prognostic factors of patients with hilar cholangiocarcinoma. World J Gastroenterol 13: 1422-1426.

31. Weber A, Landrock S, Schneider J, Stangl M, Neu B, et al. (2007) Important prognostic factors for the long-term survival of subjects with primary liver cancer in Taiwan: A hyperendemic area. Eur J Cancer 43: 1076- 1084.

32. Chou FF, Sheen-Chen SM, Chen YS, Chen MC, Chen CL (1997) Surgica treatment of cholangiocarcinoma. HepatoGastroenterology 44: 760-765.

33. Kim HJ, Yun SS, Jung KH, Kwun WH, Choi JH (1999) Intrahepatic cholangiocarcinoma in Korea. J Hepatobiliary Pancreat Surg 6: 142-148.

34. Isa T, Kusano $T$, Shimoji $H$, Takeshima $Y$, Muto $Y$, et al. (2001) Predictive factors for long-term survival in patients with intrahepatic cholangiocarcinoma. Am J Surgery 181: 507-511. 